\title{
Prevalence and Etiologic Factors of Non Carious Cervical Lesions among Prison's Population in Dakar
}

\author{
Faye $\mathrm{B}^{{ }^{1}}$, Sarr $\mathrm{M}^{1}$, Benoist $\mathrm{FL}^{1}$, Ndiaye $\mathrm{D}^{1}$, Bane $\mathrm{K}^{1}$, Lo $\mathrm{CM}^{2}$ and Toure $\mathrm{B}^{1}$ \\ ${ }^{1}$ Department of Conservative Dentistry and Endodontics University Cheikh Anta Diop-Dakar \\ ${ }^{2}$ Department of Public health University Cheikh Anta Diop-Dakar
}

${ }^{*}$ Corresponding author: Faye Babacar, Department of Conservative Dentistry and Endodontics University Cheikh Anta Diop-Dakar, BP 10006 Dakar-Liberte, Senegal, Tel: 00 221776343125, E-mail: babsfaye@yahoo.com

Citation: Faye B, Sarr M, Benoist FL, Ndiaye D, Bane K, et al. (2015) Prevalence and Etiologic Factors of Non Carious Cervical Lesions among Prison's Population in Dakar. J Dent Oral Care Med 1(3): 303. doi: 10.15744/2454-3276.1.303

Received Date: September 02, 2015 Accepted Date: November 05, 2015 Published Date: November 06, 2015

\begin{abstract}
Background: The last two decades have provided a plethora of new studies concerning noncarious cervical lesions. Most significant studies are reviewed and integrated into a practical approach to the understanding and designation of abrasion, abfraction and erosion.

Aim: Evaluate the prevalence and the etiologic factors of the Noncarious Cervical Lesions in prison's population of Dakar.

Methods and Material: Through a cross-sectional and descriptive study, prisoners of 3 prisons (Camp Penal and prisons for women of Liberty VI and Rufisque) were examinated. We used a sterile plate of examination and a card of data collection. The lesions have to include the cervical portion of the root and a radicular part of the tooth.

Results: A global prevalence of $36.8 \%$ was recorded among 375 prisoners examinated. This frequency analyzed according to the type of lesion indicates that abfraction accounted for $61.60 \%$, erosion $26.08 \%$ and abrasion $12.32 \%$.

Conclusion: These high prevalence should require more attention of the health authorities.

Keywords: Abfraction; Abrasion; Erosion; Prevalence; Prison's population
\end{abstract}

\section{Clinical Significance}

To understand the role of stress in the occurrence of noncarious cervical lesions. Preventive measures may be instituted if the causative factors are detected and their modifying factors are considered.

\section{Introduction}

Noncarious cervical lesions (NCCLs) are pathological processes characterized by the hard tissue dental loss at the cement-enamel junction (CEJ) independent of bacterial process [1,2]. This tooth structure loss is routinely found and increasingly common in dentistry clinical practice [3]. If the pathogenesis of the carious disease is known and it well codified treatment, it is not the same for non-carious pathology. Historically, abrasion was the first non-carious cervical lesion with being described by Miller [1]. It is about a pathological wear of hard surfaces of the tooth due to a mechanical process implying of the foreign objects introduced regularly into the mouth and in contact with the teeth [2]. According to the etiology, it can be diffused or localized [3-6]. The second described lesion was the erosion caused by a mainly acid chemical attack which can be of extrinsic origin, intrinsic or idiopathic. Following the introduction of the term abfraction by Grippo [7], to represent the microfracture of tooth substance in areas of stress concentration, the term remains misconstrued and misused Published studies have demonstrated the effects of stress combined with acids and enzymatic proteases as being factors in the genesis of NCCLs. Unfortunately, the term abfraction has become a "buzzword," implying a single etiology, and is frequently used erroneously to designate all NCCLs [8]. The clinician should consider all etiologic and modifying factors before completing the diagnosis or initiating treatment if indicated. Actually the notion of "biocorrosion" has been introduced to supplant erosion, according to Grippo [8] the term "biocorrosion" embraces the chemical, biochemical, and electrochemical degradation of tooth substance caused by endogenous and exogenous acids, proteolytic agents, as well as the piezoelectric effects only on dentin. Indeed, the offset forces occlusal will involve on the level of this area, more fragile, of the microscopic cracks which secondarily will fill of water and will lead to a dislocation of enamel and dentine [9]. Studies also suggest that stress may be a cofactor in the etiology of carious, especially of cervical or root carious $[10,11]$. A better knowledge of their prevalence and their pathogenesis makes it possible to work out strategies of prevention and adequate therapeutic assumption of responsibility for better prevention.

Thus our study proposes to determine the prevalence and the factors etiologic of the non-carious cervical lesions in the incarceration population of the area of Dakar. 


\section{Material and Method}

It is a descriptive cross-sectional study carried out in prisons in the area of Dakar: with the Camp Penal and the two prisons for women (Liberty VI and Rufisque).

\section{Sampling}

The Schwartz formula $n=t^{2} p(1-p) / m^{2}$ devoted to descriptive cross-sectional study was used to calculate the size of our sample which was of 375 prisoners. $\mathrm{n}^{=}$sample size, $\mathrm{t}^{=}$confidence level fixed at $1.96, \mathrm{p}^{=}$probability level, $\mathrm{m}^{=}$margin of error (usually set at $5 \%)$. These prisons were selected because they shelter the prisoners who are condemned to long detention. A systematic random sampling starting from the database was initially given by defining the step of survey which is equal to the report/ratio of the size of the population on the sample size. Software SPSS 10.0 then made it possible to carry out the pulling of our sample.

\section{Procedures of data acquisition}

The study had proceeded between April and June 2014 in the centers above mentioned penitentiaries in Dakar. A complete dental assessment including the anamneses, the collection of clinical information was carried out for each prisoner. The investigation was conducted by two dental surgeons.

\section{Studied variables and Instruments of collection}

The anamneses sought the data on the civil statue, the age, the sex, and the year of detention, the dietary habits, the drinks and adductions. The clinical examination consisted among others, to teeth examination, palpation of soft tissues of the mouth and studies the intermaxillary report. The inspection was done with the instruments of clinical examination: mirror, dental probes No 6 and 17 and of the sterile tweezers. The intermaxillary report was studied in the positions static and dynamic in order to detect possible occlusion disorders: facets of wear, contacts premature. All the NCCLs were noted, as well as the para functions and dysfunctions. The following criteria were retained to identify the NCCLs: for the abfraction the probe was to hang slightly to indicate a beginning notch. As for erosion it was to be in the shape of tablecloth and basin for abrasion. The lesion involved the cervical portion of the root and a root portion of the tooth. The tooth surface should be firm difficult to penetrate and noncarious appearance. The lesion has to imply the cervical portion of the root and a radicular part of the tooth. Statistical analysis of the data for the study were seized and operated by the SPSS version 10.0 software and the results expressed as percentage and averaged for analysis. The analysis Bi varied has allowed to us of crusader certain variable to determine the bond which was significant when the $\mathrm{P}<0.05$.

\section{Results}

\section{Descriptive statistic}

Three hundred and seventy five held satisfying the criteria of inclusion of our study were retained consisting in 335 male (89\%) and 40 female $(11 \%)$ (Sex ratio= 8.3). Among them $336(90 \%)$ are interned in camp penal, $31(8 \%)$ at the prison of women $(\mathrm{MAF})$ of Liberty VI and $08(2 \%)$ at the prison of the women of Rufisque. The mean age of the whole sample was 35 years with \pm 11.52 years with a minimum of 16 years and a maximum of 88 years.

\section{Distribution of the non-carious cervical lesions}

Global prevalence: Among the 375 prisoners, 138 presented noncarious cervical lesions: the recorded total prevalence was of $36.8 \%$.

Prevalence by type of lesion: Our results showed that the corrosion/abfraction accounted for $61.60 \%$, corrosion/erosion $26.08 \%$, and corrosion/abrasion $12.32 \%$ (Figure 1, 2, 3 and 4).

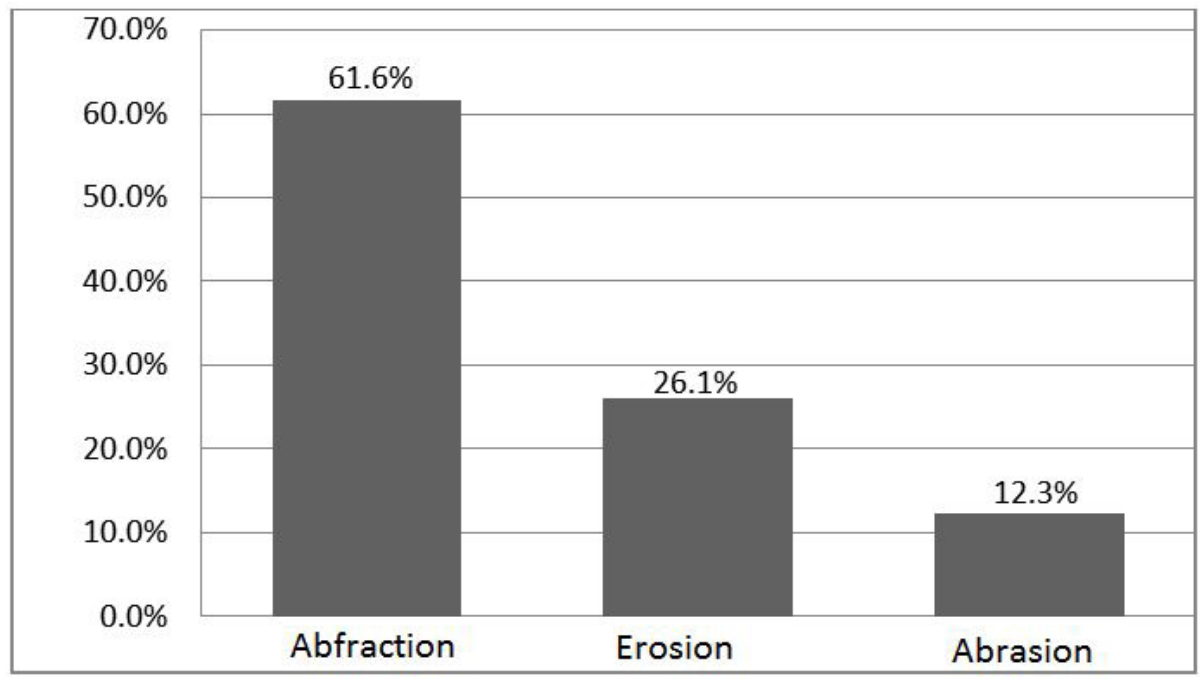

Figure 1: Prevalence by type of non-carious cervical lesion 


\section{Etiologic factors of non-carious cervical lesions}

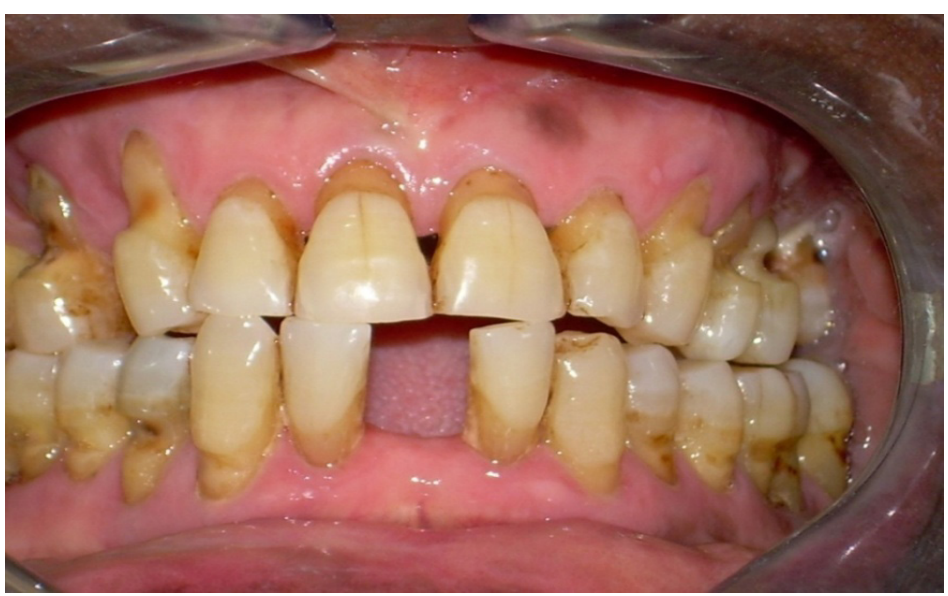

Figure 2: Corrosion/Abfraction

Statistical analysis retained two variables: bruxism and the onychophagy.

- Bruxism was significantly associated with occurred with the abfraction with Odds ratio of 2.57 and one confidence interval ranging between 1.75 and 3.1 .

- Onychophagy influenced significantly occurred of abfractives lesions with Odds ratio of 2.01 (Table1).

\begin{tabular}{|c|c|c|c|}
\hline Corrosion/Abfraction & Degree of Significativity & Odds ratio & Confidence interval \\
\hline Bruxism & 0.02 & 2.57 & $1.75-3.1$ \\
\hline Onychophagy & 0.04 & 2.01 & $1.25-3.2$ \\
\hline
\end{tabular}

Table 1: Etiologics factors of corrosion/abfraction

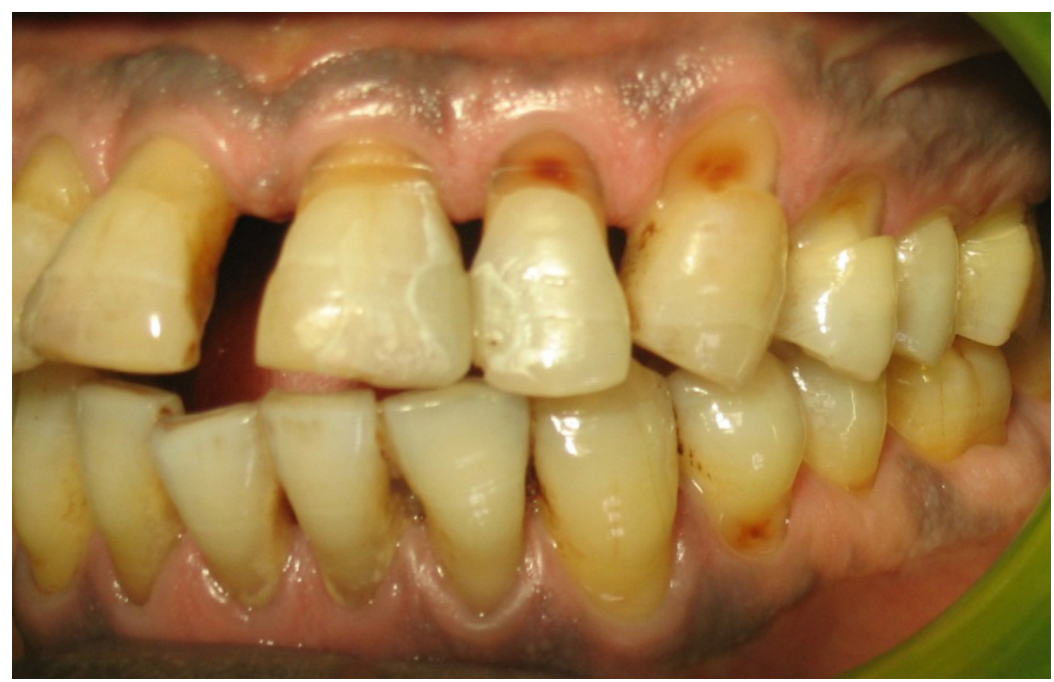

Figure 3: Corrosion/Abrasion

Three parameters were retained: the stick rubs tooth, the nature of the hairs and the technique of brushing. The use of the type of toothpaste did not find like predictive factor.

- Stick rubs teeth (29.4\%) as average of oral hygiene significantly was associated with occurred with abrasion with Odds ratio of 1.67 and one confidence interval ranging between 0.17 and 2.1 .

- Nature of the toothbrush influenced significantly occurred of abrasive lesions with Odds ratio of 3.05 and one confidence interval ranging between 1.67et 4.05.

- Technique of brushing, especially the horizontal technique (67.7\%) related to had significantly occurred of an abrasive lesion in our study (Table 2).

\begin{tabular}{|c|c|c|c|}
\hline Corrosion/Abrasion & Degree of significativity & Odds ratio & Confidence interval \\
\hline Stick rubs teeth & 0.05 & 1.67 & $0.17-2.1$ \\
\hline Nature of the toothbrushing & 0.01 & 3.05 & $1.67-4.05$ \\
\hline Technique of brushing & 0.02 & 2.08 & $0.14-3.01$ \\
\hline
\end{tabular}

Table 2: Etiologic factors of corrosion/abrasion 


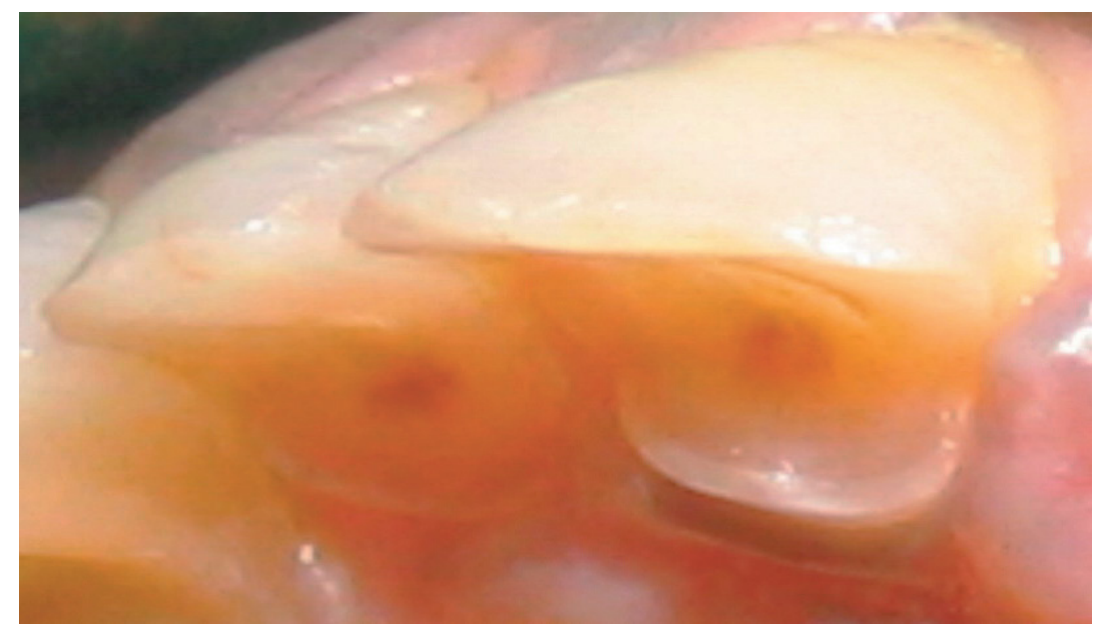

Figure 4: Corrosion/Erosion

For erosion two variables was retained: acidity of local manufactured juices and alcohol consumption (Table 3).

\begin{tabular}{|c|c|c|c|}
\hline Corrosion/Erosion & Degree of Significativity & Odds ratio & Confidence interval \\
\hline Juice (Bissap) & 0.04 & 1.9 & $0.5-2.19$ \\
\hline Alcohol & 0.07 & 0.08 & $0.16-1.29$ \\
\hline
\end{tabular}

Table 3: Etiologic factors of corrosion/erosion

\section{Discussion}

\section{Limits of our study}

The descriptive cross-sectional studies are often prone to skews. Most frequent is that of selection. The prisoners were selected that in three penal establishments of the area of Dakar. They are thus not representative of the general incarceration population. The other limiting investigator is that we did not have information on the oral state of the prisoners before their imprisonment. Thus it was difficult to establish the link between the appearance of the non-carious cervical lesions and the prison stay.

\section{Sociodemographics conditions}

The youth of the incarceration population can be explained by the development of the delinquency in the developing countries supported by precariousness. In our study the men represented more than $89 \%$ of our sample. This difference can be explained by the procedure of selection which we used. These prisons were retained according to a reasoned choice. They shelter an important incarceration population and already condemned prisoners. The penal camp which lodging only prisoners purging a sorrow higher or equal to one year becomes thus more representative.

\section{Prevalence and factors etiologics of the non-carious cervical lesions}

The aetiological agents together are able to weaken and promote tooth surface wear. NCCLs are presented in many configurations, and all of them represent, in higher or lower degree, tooth biomechanical down grade [5]. NCCLs also increase with age, which suggests a fatigue component in their formation associated with occlusal interferences or any event that changes the dental occlusion, such as tooth occlusal surface wear, restorative procedures, altered tooth position and tooth brushing behaviour, with prevalence reported in the range 5-85\% [6]. The NCCL progress is multifactorial, including acidic environment exposure and cyclic fatigue stress due to endogenous or exogenous acid substances present inside the mouth and masticatory effort, respectively [9]. The data of the literature indicate a prevalence which varies between 5 and $85 \%$ all confused lesions [11,12]. Several studies related to the various types of lesions. In a study carried out in Dakar in the general population, Faye, et al. [12] found a rate of total prevalence of $17.10 \%$ which is in accordance with our results. Compared to the type of lesion, they found that abrasion accounts for $77.70 \%$, abfraction for $12.50 \%$ and erosion for $9.80 \%$. In this present investigation abrasion accounts for $12.32 \%$ ( 17 prisoners), the abfraction $61.6 \%$ (85 prisoners) and erosion 26.08\% (36 prisoners). Our results approach those of Oginni, et al. [13] which in its study on 106 Nigerian patients found a prevalence of $37.7 \%$ of abfraction. Several studies tried to correlate these lesions with factors etiologic [2,4,6,8,10-12]. A study was conducted by Faye, et al. [14] on a non toothbrushing population with Hansen's disease (leprosy). Their preliminary study demonstrated that toothbrush/dentifrice use was not a factor in the etiology of NCCLs, which existed in 48 (47\%) of the 102 Senegalese subjects. They concluded that occlusal stress and incisal stress combined with the consumption of highly acidic beverages causing biocorrosion were the etiologic mechanisms of the NCCLs. This group was selected because they had deformed hands that precluded them from using a toothbrush. Bartlett, et al. $[15,16]$ found a relationship between gastroœsophagien reflux and palatine erosion because $64 \%$ of the patients presenting this pathology develop palatine erosion. Sadaf, et al. [17] showed in a study which the techniques of horizontal brushing produce more dental fabric loss in the form of groove than the vertical technique. In this present study the analysis of the factors etiologic revealed that all the prisoners who presented cases of erosion were exposed to an extrinsic acid source by the dietary habits (acid fruit juice or alcoholic drink abuse). For the prisoners presenting an abrasion they practiced the horizontal technique of brushing. In this work it was establish- 
ed a relation between the bruxism and the abfraction. Peutzfeldt, et al. [18] in a study bound also the existence of the abfraction to the bruxism and brings back a rate of $87 \%$ among patients with bruxism. The etiology is still controversial and a new concept of corrosion and biocorrosion has been introduced [8]. A plethora of new studies concerning such lesions have been made in this last years [8,17-21]. The most significant studies are reviewed and integrated into a practical approach to the understanding and designation of these lesions [5]. Others studies should be made to achieve the complete relationship between all kinds and shapes of NCCL and oral environment situations involved. For the treatment of these lesions many study have revealed the improvements in resin composite restorative materials, and in adhesive techniques, in fact it has become possible to rehabilitate eroded dentitions in a less invasive manner [22-24].

\section{Conclusion}

The high prevalence of the non-carious cervical lesion in this study must draw the attention of the decision makers because these abandoned non-carious cervical lesions with their natural evolution lead to dentinal hypersensibility and important functional difficulties.

\section{Acknowledgement}

The authors would like to thank the authorities of the prison's centers in Dakar for allowing us to conduct this study.

\section{References}

1. Miller WD (1907) Experiments and observation on the following of the tooth tissue variously designated as erosion, abrasion, and denudation. Dent Cosm 49: $1-23$.

2. Osborne-Smith KL, Burke FJ, Wilson NH (1999) The aetiology of the non-carious cervical lesion. Int Dent J 49: 139-43.

3. Heasman PA, Holliday R, Bryant A, Preshaw PM (2015) Evidence for the occurrence of gingival recession and non-carious cervical lesions as a consequence of traumatic toothbrushing. J Clin Periodontol 42: S237-55.

4. Wiegand A, Schlueter N (2014) The role of oral hygiene: does toothbrushing harm? Monogr Oral Sci 25: 215-9.

5. Shetty SM, Shetty RG, Mattigatti S, Managoli NA, Rairam SG, et al. (2013) No carious cervical lesions: Abfraction. J Int Oral Health 5: 143-6.

6. Antonelli JR, Hottel TL, Brandt R, Scarbecz M, Patel T (2013) The role of occlusal loading in the pathogenesis of non-carious cervical lesions. Am J Dent 26: 86-92.

7. Grippo JO (1991) Abfraction: a new classification of hard tissue lesions of teeth. J Esthet Dent 1: 14-9.

8. Grippo JO, Simring M, Coleman TA (2012) Abfraction, abrasion, biocorrosion, and the enigma of noncarious cervical lesions: a 20-year perspective. J Esthet Restor Dent 24: 10-23.

9. Soares PV, Santos-Filho PC, Soares CJ, Faria VL, Naves MF, et al (2013) Non-carious cervical lesions: influence of morphology and load type on biomechanical behaviour of maxillary incisors. Aust Dent J 58: 306-14.

10. Senna P, Del Bel Cury A, Rösing C (2012) Non-carious cervical lesions and occlusion: a systematic review of clinical studies. J Oral Rehabil 39: 450-62.

11. Guimarães JC, Guimarães Soella G, Brandão Durand L, Horn F, Narciso Baratieri L, et al. (2014) Stress amplifications in dental non-carious cervical lesions. J Biomech $47: 410-6$.

12. Faye B, Sarr M, Kane AW, Toure B, Leye F, et al. (2005) Prevalence and etiologic factors of non-carious cervical lesions. A study in a Senegalese population. Odontostomatol Trop 28: 15-8.

13. Oginni AO, Adeleke AA (2014) Comparison of pattern of failure of resin composite restorations in non-carious cervical lesions with and without occlusal wear facets. J Dent 42: 824-30.

14. Faye B, Kane AW, Sarr M, Lo C, Ritter AV, et al. (2006) Noncarious cervical lesions among a non-toothbrushing population with Hansen's disease (leprosy): initial findings. Quintessence Int 37: 613-9.

15. Bartlett DW, Shah P (2006) A critical review of non-carious cervical (wear) lesions and the role of abfraction, erosion, and abrasion. J Dent Res 85: 306-12.

16. Bartlett D (2009) Etiology and prevention of acid erosion. Compend Contin Educ Dent 30: 616-20.

17. Sadaf D, Ahmad Z (2014) Role of Brushing and Occlusal Forces in Non-Carious Cervical Lesions (NCCL). Int J Biomed Sci 10: 265-8.

18. Peutzfeldt A, Jaeggi T, Lussi A (2014) Restorative therapy of erosive lesions. Monogr Oral Sci 25: 253-61.

19. Walter C, Kress E, Götz H, Taylor K, Willershausen I, et al. (2014) The anatomy of non-carious cervical lesions. Clin Oral Investig 18: 139-46.

20. Antonelli JR, Hottel TL, Brandt R, Scarbecz M, Patel T (2013) The role of occlusal loading in the pathogenesis of non-carious cervical lesions. Am J Dent 26: 86-92.

21. Antonelli JR, Hottel TL, Garcia-Godoy F (2013) Abfraction lesions--where do they come from? A review of the literature. J Tenn Dent Assoc 93: 14-9.

22. Jakupovic S, Cerjakovic E, Topcic A, Ajanovic M, Prcic AK, et al. (2014) Analysis of the abfraction lesions formation mechanism by the finite element method. Acta Inform Med 22: 241-5.

23. Colon P, Lussi A (2014) Minimal intervention dentistry: part 5. Ultra-conservative approach to the treatment of erosive and abrasive lesions. Br Dent J 216: 463-8.

24. Peumans M, De Munck J, Mine A, Van Meerbeek B (2014) Clinical effectiveness of contemporary adhesives for the restoration of non-carious cervical lesions. A systematic review. Dent Mater 30: 1089-103. 


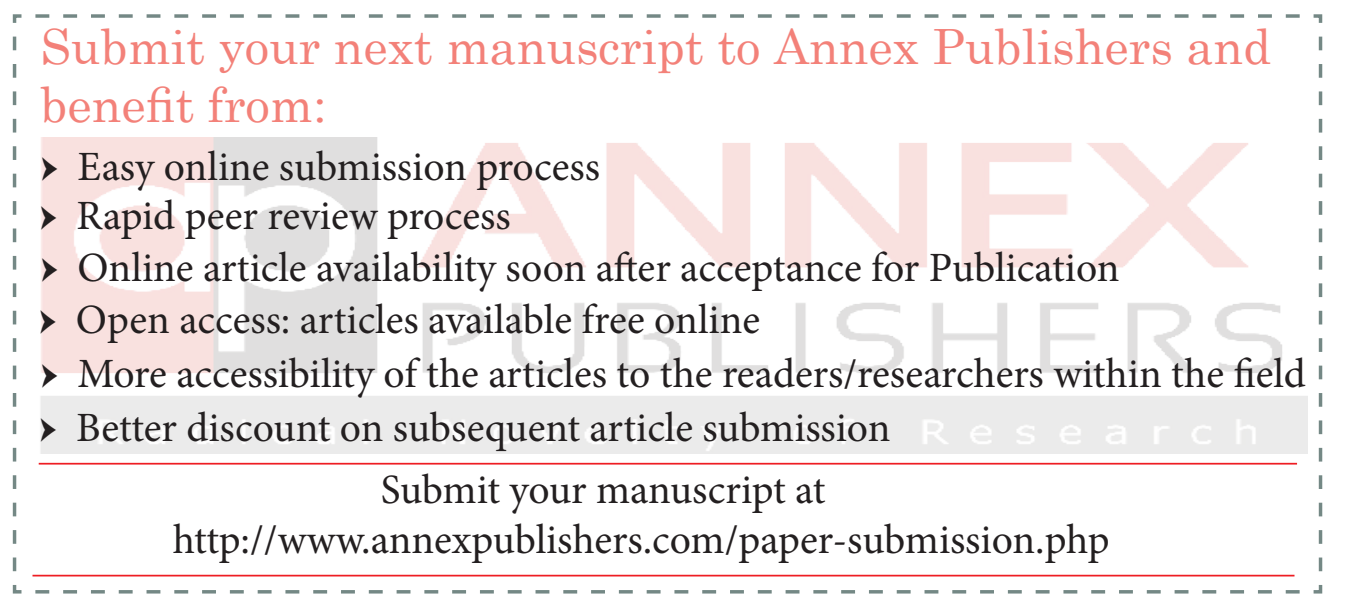

